www.jmscr.igmpublication.org

Impact Factor (SJIF): 6.379

Index Copernicus Value: 71.58

ISSN (e)-2347-176x ISSN (p) 2455-0450

crossref DOI: _https://dx.doi.org/10.18535/jmscr/v6i2.13

Journal Of Medical Science And Clinical Research

\title{
A Comparative Study of Pro Seal Laryngeal Mask Airway, i-gel and Combitube under General Anaesthesia for Elective Surgical Patients Requiring Controlled Ventilation
}

\author{
Authors \\ Ravi Anand ${ }^{1}$, Amar Nath Gupta ${ }^{2}$, Avinash Kumar ${ }^{3}$ \\ ${ }^{1}$ Senior Resident, Department of Anaesthesiology, GIMSH, Durgapur \\ ${ }^{2}$ Assistant Professor, Department of Anaesthesiology, GIMSH, Durgapur \\ ${ }^{3}$ Senior Resident, Department of Anaesthesiology, GIMSH, Durgapur \\ *Corresponding Author \\ Dr Amar Nath Gupta
}

Assistant Professor, Department of Anaesthesiology, Gouri Devi Institute of Medical Sciences and Hospital,

Durgapur, West Bengal, India

Email: drravianand75@yahoo.com

\begin{abstract}
Aim: The Pro Seal laryngeal mask airway (PLMA), i-gel and Combi Tube (CT) in past evaluated alone or in group comparisons but differing study designs make it difficult to compare the results. The aim of this study was to compare the clinical performance of these three alternative devices in terms of efficacy and safety in patients receiving mechanical ventilation during elective surgical procedures.

Material and Methods: This prospective, randomised, double blind study was performed in randomly allocated 3 different groups containing each group 30 American Society of Anesthesiologists physical status I-II patients, undergoing elective surgical procedures under general anaesthesia. PLMA, i-gel or CT appropriate for weight orland height was inserted. Primary outcome measured was airway sealing pressure. Insertion time, ease of insertion, number of attempts, overall success rate and the incidence of airway trauma and complications were also recorded. Intergroup differences were compared using one way analysis of variance with post hoc correction for continuous data and Chi-square test for categorical variables.

Results: Overall success rate was comparable between the three devices (i-gel 100\%, CT 100\%, PLMA 96.6\%). Airway sealing pressure was lower with i-gel (24.26 $\pm 1.96 \mathrm{~cm} \mathrm{H2O})$ compared to CT $(26.52 \pm$ $2.11 \mathrm{~cm} \mathrm{H2O})$ and PLMA (28.6 $\pm 2.5 \mathrm{~cm} \mathrm{H2O} ; \mathrm{P}<0.0005)$. The mean insertion time was significantly more in PLMA (37.22 $\pm 2.9 \mathrm{~s})$ compared to $i$-gel (26.9 $\pm 2.53 \mathrm{~s})$ and CT (22.22 $\pm 2.31 \mathrm{~s} ; P<0.0005)$.

Conclusion: Airway sealing pressure and insertion time were significantly higher in PLMA compared to $i$ gel and $C T$.

Keywords: Airway management, Artificial, i-gel, Combi tube, Pro Seal laryngeal mask airway, respiration
\end{abstract}

\section{Introduction}

Maintenance of a clear upper airway is the basic aspect of the practice of general anaesthesia.
Airway management of patients has progressed from introduction of endotracheal tube (ETT) to the less invasive laryngeal mask airway (LMA). ${ }^{[1]}$ 
In the past 10 years, there has been a phenomenal increase in the use of supraglottic airway devices (SADs) for elective and rescue purposes. Several second generation devices, including the Pro Seal laryngeal mask airway (PLMA, LMA North America, San Diego, CA), i-gel supraglottic airway device (Intersurgical Ltd, Wokingham, Berkshire, UK) and Combitube ${ }^{\circledR}$

(Tyco-Kendall, Argyle, NY, USA) have been introduced over the past decade. ${ }^{[2,3]}$ In this study, we compared PLMA, CT and i-gel LMA under general anaesthesia for elective surgeries. Primary outcome measure was airway sealing pressure along with comparison of insertion time, ease of insertion, number of attempts, overall success rate and the incidence of airway trauma and complications.

\section{Material and Methods}

After Institutional Ethical Committee clearance, 90 patients of either sex belonging to ASA grade-I \& II aged 20-65 years and Body Mass Index (BMI) between $15-30 \mathrm{Kg} / \mathrm{m}^{2}$ undergoing elective surgical procedures of duration $1-1 \frac{1}{2} \mathrm{~h}$ not requiring endotracheal intubation were studied in a randomized prospective study, designed to compare PLMA with i-gel and CT. The exclusion criteria included patients with risk factors for difficult airway (mouth opening of $<3$ finger, Modified Mallampati Score $3 \& 4$, limited neck movement, previous history of difficult intubation), any known pulmonary and cardiovascular diseases and risk of aspiration (full stomach, hiatus hernia, gastro oesophageal reflux disease, emergency surgery). Neck Movement was assessed as Class: I-No reduction in movement, II-1/3rd reduction, III-2/3rd reduction, IV Complete reduction.

After complete pre anaesthetic check-up, informed written consent was obtained from all patients fulfilling the required criteria. 90 patients were equally randomised by block randomisation to three groups, namely, Group I (i-gel, $n=30$ ), Group P (PLMA, $n=30$ ) and Group C (CT, $n=$ 30) using computer generated randomisation programme by an anaesthetist who was not involved in the operating room procedure. Participants were assigned to specific groups by the anaesthesia technician.

After attaching multipara monitor (pulse oximeter, non invasive blood pressure and electrocardiography), patients were pre medicated with injection midazolam $0.05 \mathrm{mg} / \mathrm{kg}$, glycopyrrolate $0.2 \mathrm{mg}$, and fentanyl $2 \mathrm{mcg} / \mathrm{kg}$ intravenously. All patients were pre-oxygenated for $3 \mathrm{~min}$, and anaesthesia was induced with injection propofol 2 $\mathrm{mg} / \mathrm{kg}$. Injection vecuronium $0.1 \mathrm{mg} / \mathrm{kg}$ was given for neuromuscular blockade and patients were ventilated with oxygen for 3 mins till complete relaxation set in.

Size of PLMA or CT or i-gel appropriate for weight or/and height (as in case of CT) of patient was selected, lubricated with water soluble jelly and inserted as per the manufacturers guidelines.

After successful insertion, the cuff of PLMA and CT were inflated with air according to the size and as per recommended manufacturers guidelines, to prevent audible and palpable air leak. An effective airway was confirmed by bilateral symmetrical chest expansion on manual ventilation, auscultation of breath sounds, square waveform on capnography, stable oxygen saturation, no audible leak of the gases and lack of gastric insufflation. Devices were fixed with adhesive tape applied to the maxilla on one side of the patient's face and passed over and under the tube in a single loop before fixing to the opposite maxilla.

Anaesthesia was maintained with oxygen, nitrous oxide and halothane and intermittent positive pressure ventilation. Haemodynamic parameters were monitored after the insertion of the device. A lubricated gastric tube was placed in the stomach through the gastric channel. At the end of surgical procedure, anaesthesia was discontinued and residual neuromuscular blockade reversed with injection neostigmine and glycopyrrolate, followed by device removal. Complication if any was noted. 
We assessed number of insertion attempts, ease of insertion, time of insertion, airway sealing pressure, number of attempts of gastric tube insertion and complications. One attempt was defined as picking up of the device and negotiating it beyond the incisors. In case of insertion attempts, maximum of three attempts were allowed. An attempt was considered unsuccessful, if there was failure to negotiate the device beyond oropharynx, significant leak present (both audible and auscultatory) or inadequate ventilation with $\mathrm{EtCO} 2>45 \mathrm{mmHg}$. Failure of a device was defined as three unsuccessful insertion attempts or inadequate ventilation. After failure of three attempts, intubation was performed using conventional rigid laryngoscopy and case was recorded as failed and also deleted from the study.For ease of insertion of device, it was termed easy, if device was inserted in a single attempt/manoeuvre in to the pharynx with no resistance to insertion. It was termed difficult if there was resistance to insertion or more than one manoeuvre/attempt was required for correct placement of the device. Insertion time was defined as time interval (in seconds) between placing the device into the oral cavity and securing an effective airway, which was recorded by an independent observer. Effective airway was confirmed by auscultation and square wave pattern on EtCO2. The airway sealing pressure was measured by closing the expiratory valve of the circle system at a fixed gas flow of $3 \mathrm{~L} / \mathrm{min}$ and recording the airway pressure at which equilibrium is reached. At this stage, a leak at mouth and stomach was ascertained. A maximum of two attempts were allowed for gastric tube placement. Its correct placement was confirmed by injection of air and epigastric auscultation or aspiration of gastric contents. Failure was defined as inability to advance the orogastric tube into the stomach within two attempts. Blood staining of the device and tongue, lip or dental trauma was noted. Incidence of laryngospasm or hypoxia (defined as oxygen saturation $<92 \%$ ), if any, in intra operative period was noted and managed accordingly. In post-operative period, an investigator blinded to study asked the patients about the signs of sore throat, dysphagia and hoarseness of voice. Incidence of hoarseness and sore throat, whether present or absent, were enquired in $24 \mathrm{~h}$ post-operatively.

The primary outcome measure of the study was airway sealing pressure. We hypothesised that the airway sealing pressure of PLMA would be higher than i-gel and CT. Based on a previous study by Jadhav et al., ${ }^{[4]}$ we found mean airway sealing pressure in PLMA group as $25.73 \mathrm{cmH} 2 \mathrm{O}$ and SD of 2.21. Based on that, taking alpha 0.05 , $\hat{a}=0.8$ and $25 \%$ difference between the means as significant, we calculated 28 patients were required in each group; hence, the sample size was increased to 30 patients each.

The data were recorded in a Microsoft Excel Spreadsheet and analysed using SPSS statistics software version 24 (IBM SPSS Inc., Chicago, IL, USA). Continuous numerical variables were presented as mean (standard deviation) and intergroup differences were compared using one way analysis of variance with post hoc correction. Categorical variables were presented as ratio or as $n(\%)$ and inter-group differences were compared using Chi square test. The $P<0.05$ was considered statistically significant.

\begin{tabular}{|c|c|c|c|}
\hline Parameters & $\begin{array}{l}\text { Group I } \\
(n=30)\end{array}$ & $\begin{array}{l}\text { Jroup C } \\
(n=\mathbf{3 0})\end{array}$ & $\begin{array}{c}\text { Group P } \\
(n=30)\end{array}$ \\
\hline Age (years) & $42.54 \pm 13.8$ & $41.46 \pm 12.29$ & $42.78 \pm 12.7$ \\
\hline Gender (female/m & Iale) $19 / 11$ & $16 / 14$ & $17 / 13$ \\
\hline ASA (I/II) & $20 / 10$ & $22 / 08$ & $24 / 06$ \\
\hline MMPS(I/II) & $26 / 04$ & $22 / 08$ & $25 / 05$ \\
\hline $\begin{array}{l}\text { Neck movement } \\
\text { (Class I/II/III/IV) }\end{array}$ & $26 / 4 / 0 / 0$ & $27 / 3 / 0 / 0$ & $27 / 3 / 0 / 0$ \\
\hline Weight (kg) & $54.9 \pm 3.59$ & $53.32 \pm 3.71$ & $55.04 \pm 4.18$ \\
\hline Height $(\mathrm{cm})$ & $155.22 \pm 6.79$ & $157.34 \pm 6.62$ & $158.46 \pm 4.91$ \\
\hline $\begin{array}{l}\text { Surgical duration } \\
(\min )\end{array}$ & $62.3 \pm 9.94$ & $63.5 \pm 10.94$ & $65.1 \pm 13.56$ \\
\hline
\end{tabular}

\section{Result}

There was no statistical difference in demographic data between the three groups [Table 1]. The mean time for the effective placement of device was lowest for CT $(22.22 \pm 2.31 \mathrm{~s})$, followed by i- 
gel $(26.9 \pm 2.53$ s). PLMA group had the maximum mean insertion time of $(37.22 \pm 2.9 \mathrm{~s})$ of all the three devices $(P<0.0005)$. Overall success rate for insertion of the three devices was comparable, and it was $100 \%, 100 \%$ and $96.6 \%$, respectively, for Group I, Group C and Group P after three attempts. PLMA had the highest mean airway sealing pressure $(28.6 \pm 2.5 \mathrm{~cm} \mathrm{H} 2 \mathrm{O})$ compared to i-gel $(24.26 \pm 1.96 \mathrm{~cm} \mathrm{H} 2 \mathrm{O})$ and CT $(26.52 \pm 2.11 \mathrm{~cm} \mathrm{H} 2 \mathrm{O})(P<0.0005)$. The rate of success of gastric tube insertion through i-gel, CT and PLMA was 96.6\%, 93.3\%, 100\%, respectively [Table 2]. With regard to adverse events, no differences were found in the number of episodes of laryngospasm and hypoxia between the three devices. Traces of blood at removal of the device were reported with 2 patients each of $\mathrm{CT}$ and i-gel, and in 1patients with PLMA. One patient with blood stained CT also presented with sore throat $1 \mathrm{~h}$ after surgery.

\section{Discussion}

This study compared the performance of three different second generation supraglottic airway devices (SADs) in elective surgical cases under general anaesthesia with controlled ventilation. The main findings are that the most suitable devices for use in this scenario are the PLMA and i-gel airway, where i-gel had better insertion characteristics and PLMA had higher sealing pressure. The CT had the shortest insertion time with similar insertion success as compared to igel. Most attributes of the Combitube described in the literature are assumed to be valid for the CT. ${ }^{[5,6]}$ The results of our study can be compared with other evidence related to second generation SADs. The first attempt insertion success achieved in our study was comparable to data from multiple studies. ${ }^{[7-12]}$ The ease of insertion was similar for all the devices. However, the i-gel showed a higher probability of insertion success without resistance than the PLMA and CT of all the successful insertions which may be partly explained by the non inflatable cuff in the i-gel. Difficulties in PLMA insertion can be due to its large cuff, which can impede digital intraoral positioning and propulsion into the pharynx, and also, the lack of a back plate which makes the cuff more likely to fold over at the back of the mouth. ${ }^{[13]}$ Although the insertion time for CT was less than other two devices of our study, its harder distal end may make it more prone to produce trauma during insertion .

Insertion time was shorter with the i-gel than with the PLMA; similar results have been seen in various studies in the past. ${ }^{[14,15]}$ The i-gel is considered easier to insert due to its unique gel like thermo plastic material, shape and contour, buccal stabilizer and epiglottis blocker which minimises epiglottis down folding. Furthermore, the studies from the past indicate a near similar insertion time between PLMA and CT. ${ }^{[10-12,16]}$ In our study, we report mean insertin time of CT being significantly lower than i-gel and PLMA. This may be because CT has a unique profile and requires little or no manipulation at all for insertion into oropharynx. When extra resistance is felt during insertion of the CT, the possibility of tracheal insertion should be considered. ${ }^{[16]}$ Moreover, studies comparing insertion time between i-gel and CT are limited and require further evaluation with future discourse. In the previous study by Weksler $\mathrm{N}$ et al., CT had a mean insertion time of $18 \mathrm{~s}$ and PLMA of $20 \mathrm{~s}$, the difference being statistically insignificant. ${ }^{[17]}$

\begin{tabular}{|c|c|c|c|}
\hline Parameter & $\begin{array}{l}\text { Group I } \\
(n=30)\end{array}$ & $\begin{array}{c}\text { Group C } \\
(n=30)\end{array}$ & $\begin{array}{l}\text { Group P } \\
(n=30)\end{array}$ \\
\hline $\begin{array}{l}\text { Insertion } \\
\text { Attempts } \\
\text { (1st/2nd/3rd/fail) }\end{array}$ & $25 / 5 / 0 / 028 /$ & $2 / 0 / 026 / 3 / 0 / 1$ & 0.307 \\
\hline $\begin{array}{l}\text { Overall success } \\
\text { rate }(\%)\end{array}$ & 100 & 100 & 96.6- \\
\hline $\begin{array}{l}\text { Ease of insertion } \\
\text { (easy/difficult) }\end{array}$ & $28 / 226 / 4$ & $25 / 5$ & 0.799 \\
\hline Insertion times(s) 26 & $6.9 \pm 2.53 \quad 22$ & $.22 \pm 2.31 \quad 37$ & $2 \pm 2.9<0.0005$ \\
\hline $\begin{array}{l}\text { Airway sealing } \\
\text { pressure }(\mathrm{cmH} 2 \mathrm{O})\end{array}$ & $24.26 \pm 1.96$ & $26.52 \pm 2.11$ & $3.6 \pm 2.5<0.0005$ \\
\hline $\begin{array}{l}\text { Number of } \\
\text { attempts in drain tube } \\
\text { placement }(1 \mathrm{st} / 2 \mathrm{nd} / \mathrm{fai}\end{array}$ & ail) & $5 / 3 / 2 \quad 29 / 1 / 0$ & 0.654 \\
\hline
\end{tabular}


There was difference in definition of insertion time and ease of insertion between the studies. Different studies allowed different numbers of attempts as successful insertion (two to three) before considering it as a failure. The use of neuromuscular blocking drugs and the experience of the person inserting the device may also affect the ease and insertion time for airway devices. These potential methodological differences could be responsible for the heterogeneity associated between devices as seen in the literature. The subjective nature of this assessment may have introduced a bias. Airway sealing pressure has been commonly used to assess successful airway placement in SAD studies. The leak pressure is an important indicator of both the success of positive pressure ventilation and the degree of airway protection. ${ }^{[18]}$ In two systemic reviews and meta analyses, ${ }^{[19,20]}$ there was clear superiority of PLMA in comparison to i-gel in terms of airway sealing pressure in mechanically ventilated patients with neuromuscular blockers. Design changes in the PLMA that make it a more effective ventilatory device include a second cuff attached to the dorsal surface, which pushes the ventral cuff more firmly into the periglottic tissue $^{[21]}$ and a ventral cuff that is larger proximally, to improve the seal by plugging potential gaps. As a result, it provides a better seal that equates to higher tidal volumes without leak. This may be of particular relevance in patients receiving high airway pressure, such as obese patients undergoing intra abdominal or laparoscopic surgery, patients in the lithotomy position, patients undergoing surgery in the head down position or patients with restrictive pulmonary disease. ${ }^{[13]}$ Our findings for complications with use of the three devices are similar to the results obtained by other authors. ${ }^{[16,22,23]}$ Soliveres et al. found that the use of PLMA produced more sore throat as compared to the i-gel. ${ }^{[24]}$ Various studies have reported similar findings, wherein the incidence of sore throat is minimal with i-gel in comparison with other supraglottic airway devices. ${ }^{[25-28]}$ Majority of the patients from our study did not have post-operative sore throat, which could be due to the high success rate in first insertion attempts in all the groups. During the course of our study, we also observed certain limitations. It was not possible to eliminate potential researcher bias because of his awareness of the device being used. Fibreoptic assessment of studied airway tools position was not performed. Neuromuscular monitor to assess the adequacy of block during tube insertion was not used; clinical signs to judge the same were exercised. All insertions were performed by a single experienced anaesthesiologist; therefore, our results may not be generalised. The results also may not be applicable to novice users. This study was carried out on ASA I and II physical status and patients with normal airways; thus, further trials are recommended to include both high risk patients and those with anticipated difficult airways. The oropharyngeal leak pressure was only measured once, at the start of the procedure, although the leak pressure is a dynamic entity and may change over time.

\section{Conclusion}

The airway sealing pressure of PLMA was higher compared to i-gel and CT, but the insertion time of CT was least among the three devices.

\section{References}

1. Yarrow S, Hare J, Robinson KN. Recent trends in tracheal intubation: A retrospective analysis of 97904 cases. Anaesthesia 2003;58:1019-22.

2. Cook TM, Woodall N, Frerk C, Fourth National Audit Project. Major complications of airway management in the UK: Results of the fourth national audit project of the Royal College of Anaesthetists and the Difficult Airway Society. Part 1: Anaesthesia. $\quad \mathrm{Br} \quad \mathrm{J}$ Anaesth 2011;106:617-31. 
3. Asai T, Morris S. The laryngeal mask airway: Its features,effects and role. Can J Anaesth 1994;41:930-60.

4. Jadhav PA, Dalvi NP, Tendolkar BA. I-gel versus laryngeal mask airway-proseal: Comparison of two supraglottic airway devices in short surgical procedures. $\mathbf{J}$ AnaesthesiolClinPharmacol

2015;31:221-5.

5. Amini A, Zand F, Maghbooli $M$. Disposable versus reusable laryngeal tube suction for ventilation in patients undergoing laparoscopic cholecystectomy. Rev Bras Anestesiol 2010;60:32-41.

6. Brimacombe J, Keller C. The ProSeal laryngeal mask airway: A randomized, crossover study with the standard laryngeal mask airway in paralyzed, anesthetized patients. Anesthesiology 2000;93:104-9.

7. Kannaujia A, Srivastava U, Saraswat N, Mishra A, Kumar A,Saxena S, et al. A preliminary study of I-gel: A new supraglottic airway device. Indian $\mathbf{J}$ Anaesth 2009;53:52-6.

8. Liew GH, Yu ED, Shah SS, Kothandan H. Comparison of the clinical performance of I-gel, LMA supreme and LMA ProSeal in elective surgery. Singapore Med J 2016;57:432-7.

9. Cook TM, Lee G, Nolan JP. The ProSeal laryngeal mask airway:A review of the literature. Can J Anaesth 2005;52:739-60.

10. Morteza Saeedi, Houman Hajiseyedjavadi, Javad Seyedhosseini, et al. Comprarison of endotracheal intubation, combitube, and laryngeal mask airway between inexperienced and experienced emergency medical staff: A manikin studyInt J CritIllnInj Sci. 2014; 4(4): 303308

11. Bein B, Carstensen S, Gleim M, Claus L, Tonner $\mathrm{PH}$, Steinfath $\mathrm{M}$, et al. A comparison of the proseal laryngeal mask airway, the laryngeal tube $\mathrm{S}$ and the oesophageal-tracheal combitube during routine surgical procedures. Eur J Anaesthesiol. 2005;22:341-6

12. Cavus E, Deitmer W, Francksen H, Serocki G, Bein B, ScholzJ,et al. Laryngeal tube S II, ProSeal laryngeal mask, and EasyTubeduring elective surgery: A randomized controlled comparison with the endotracheal tube in nontrained professionals. Eur J Anaesthesiol 2009;26:730-5.

13. Brimacombe J, Keller C, Boehler M, Pühringer F. Positive pressure ventilation with the ProSeal versus classic laryngeal mask airway: A randomized, crossover study of healthy female patients. Anesth Analg 2001;93:1351-3.

14. Kini G, Devanna GM, Mukkapati KR, Chaudhuri S, Thomas D.Comparison of I-gel with proseal LMA in adult patients undergoing elective surgical procedures under general anesthesia without paralysis: A prospective randomized study $\mathbf{J}$ Anaesthesiol Clin Pharmacol 2014; 30:183-7.

15. Nirupa R, Gombar S, Ahuja V, Sharma P. A randomised trial to compare i-gel and ProSeal ${ }^{\mathrm{TM}}$ laryngeal mask airway for airway management in paediatric patients. Indian J Anaesth 2016;60:726-31.

16. Rumball CJ, MacDonald D. The PTL, Combitube, laryngeal mask, and oral airway: A randomized prehospital comparative study of ventilatory device effectiveness and cost-effectiveness in 470 cases of cardiorespiratory arrest. Prehosp Emerg Care. 1997;1:1-10

17. Weksler N, Tarnopolski A, Klein M, Schily M, Rozentsveig V, Shapira AR, et al. Insertion of the endotracheal tube, laryngeal mask airway and oesophagealtracheal Combitube. A 6-month comparative prospective study of acquisition and retention skills by medical 
students. Eur JAnaesthesiol. 2005;22:33740.

18. Seet E, Rajeev S, Firoz T, Yousaf F, Wong J, Wong DT, etal.Safety and efficacy of laryngeal mask airway supreme versus laryngeal mask airway ProSeal: A randomized controlled trial. Eur J Anaesthesiol 2010;27:602-7.

19. Park SK, Choi GJ, Choi YS, Ahn EJ, Kang H. Comparison of the I-gel and the laryngeal mask airway proseal during general anesthesia: A systematic review and meta-analysis. PLoS One 2015;10:e0119469.

20. Shin HW, Yoo HN, Bae GE, Chang JC, Park MK, You HS, et al. Comparison of oropharyngeal leak pressure and clinical performance of LMA ProSeal ${ }^{\mathrm{TM}}$ and I-gel ${ }^{\circledR}$ in adults: Meta-analysis and systematic review. J Int Med Res 2016;44:405-18.

21. Brimacombe J, Keller C. The ProSeal laryngeal mask airway. Anesthesiol Clin North America 2002;20:871-91.

22. Sharma B, Sehgal R, Sahai C, Sood J. PLMA vs. I-gel: A Comparative evaluation of respiratory mechanics in laparoscopic cholecystectomy. J Anaesthesiol Clin Pharmacol 2010;26:451-7.

23. Das A, Majumdar S, Mukherjee A, Mitra $\mathrm{T}$, Kundu R, HajraBK,et al. I-gel in ambulatory surgery: A Comparison with LMA-ProSeal $^{\mathrm{TM}}$ in paralyzed anaesthetized patients. J ClinDiagn Res 2014;8:80-4.

24. Soliveres J, Balaguer J, Richart MT, Sanchez J, Solaz C. Airway morbidity after use of the laryngeal mask airway LMA Proseal vs. I-gel. Eur J Anaesthesiol 2010;27:257-8.

25. Keijzer C, Buitelaar DR, Efthymiou KM, Srámek M, ten Cate J,Ronday M, et al. A comparison of postoperative throat and neck complaints after the use of the I-gel and the la premiere disposable laryngeal mask: A double-blinded, randomized, controlled trial. AnesthAnalg 2009;109: 1092-5.

26. Gasteiger L, Brimacombe J, Perkhofer D, Kaufmann M, Keller C.Comparison of guided insertion of the LMA ProSeal vs. the i-gel. Anaesthesia 2010;65:913-6.

27. Singh I, Gupta M, Tandon M. Comparison of clinical performance of I-gel with LMA-proseal in elective surgeries. Indian J Anaesth 2009;53:302-5.

28. Helmy AM, Atef HM, El-Taher EM, Henidak AM. Comparative study between I-gel, a new supraglottic airway device, and classical laryngeal mask airway in anesthetized spontaneously ventilated patients. Saudi J Anaesth 2010;4:131-6. 